\title{
Platelet-Derived Growth Factor Stimulates Bone Fill and Rate of Attachment Level Gain: Results of a Large Multicenter Randomized Controlled Trial
}

\author{
Myron Nevins, * William V. Giannobile, ${ }^{\dagger}$ Michael K. McGuire, ${ }^{\dagger}$ Richard T. Kao,§ James T. Mellonig,\|
} James E. Hinrichs, " Bradley S. McAllister," Kevin S. Murphy, ${ }^{* *}$ Pamela K. McClain, ${ }^{\dagger \dagger}$

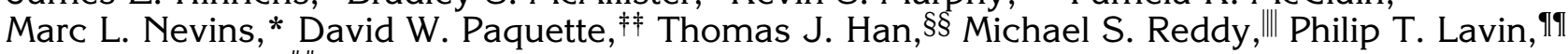
Robert J. Genco, ${ }^{\# \#}$ and Samuel E. Lynch***

Background: Growth factors are generally accepted to be essential mediators of tissue repair via well-established mechanisms of action that include stimulatory effects on angiogenesis and cellullar proliferation, ingrowth, differentiation, and matrix biosynthesis. The aim of this study was to evaluate in a large-scale, prospective, blinded, and randomized controlled clinical trial the safety and effectiveness of purified recombinant human platelet-derived growth factor (rhPDGF-BB) mixed with a synthetic beta-tricalcium phosphate ( $\beta$-TCP) matrix for the treatment of advanced periodontal osseous defects at 6 months of healing.

Methods: Eleven clinical centers enrolled 180 subjects, each requiring surgical treatment of a 4 mm or greater intrabony periodontal defect and meeting all inclusion and exclusion criteria. Subjects were randomized into one of three treatment groups: 1) $\beta$-TCP $+0.3 \mathrm{mg} / \mathrm{ml}$ rhPDGF-BB in buffer; 2$) \beta$-TCP $+1.0 \mathrm{mg} / \mathrm{ml}$ rhPDGF-BB in buffer; and 3) $\beta$-TCP + buffer (active control). Safety data were assessed by the frequency and severity of adverse events. Effectiveness measurements included clinical attachment levels (CAL) and gingival recession (GR) measured clinically and linear bone growth (LBG) and percent bone fill (\% BF) as assessed radiographically by an independent centralized radiology review center. The area under the curve (AUC), an assessment of the rate of healing, was also calculated for CAL measurements. The surgeons, clinical and radiographic evaluators, patients, and study sponsor were all masked with respect to treatment groups.

Results: CAL gain was significantly greater at 3 months for group 1 (rhPDGF $0.3 \mathrm{mg} / \mathrm{ml}$ ) compared to group 3 ( $\beta$-TCP + buffer) (3.8 versus $3.3 \mathrm{~mm} ; P=0.032$ ), although by 6 months, this finding was not statistically significant $(P=0.11)$. This early acceleration of CAL gain led to group 1 exhibiting a significantly greater rate of CAL gain between baseline and 6 months than group 3 as assessed by the AUC (68.4- versus 60.1 -mm weeks; $P=0.033)$. rhPDGF $(0.3 \mathrm{mg} / \mathrm{ml})$-treated sites also had significantly greater linear bone gain ( 2.6 versus $0.9 \mathrm{~mm}$, respectively; $P<0.001$ ) and percent defect fill ( $57 \%$ versus $18 \%$, respectively; $P<0.001)$ than the sites receiving the bone substitute with buffer at 6 months. There was less GR at 3 months in group 1 compared to group $3(P=0.04)$; at 6 months, GR for group 1 remained unchanged, whereas there was a slight gain in gingival height for group 3 resulting in comparable GR. There were no serious adverse events attributable to any of the treatments.

Conclusions: To our knowledge, this study is the largest prospective, randomized, triple-blinded, and controlled pivotal clinical trial reported to date assessing a putative periodontal regenerative and wound healing therapy. The study demonstrated that the use of rhPDGF-BB was safe and effective in the treatment of periodontal osseous defects. Treatment with rhPDGF-BB stimulated a significant increase in the rate of CAL gain, reduced gingival recession at 3 months post-surgery, and improved bone fill as compared to a $\beta$-TCP bone substitute at 6 months. J Periodontol 2005;76:2205-2215.

\section{KEY WORDS}

\section{Bone regeneration; periodontics; platelet-derived growth factor; randomized clinical trial; tissue engineering.}

\footnotetext{
* Harvard School of Dental Medicine, Boston, MA.

University of Michigan, Ann Arbor, MI.

Private practice, Houston, TX.

Private practice, Cupertino, CA.

University of Texas Health Science Center, San Antonio, TX.

University of Minnesota School of Dentistry, Minneapolis, MN.

Private practice, Portland, OR.

* * Private practice, Baltimore, MD

$\dagger$ Private practice, Aurora, CO.

市 University of North Carolina School of Dentistry, Chapel Hill, NC.

$\S \S$ Private practice, Los Angeles, CA.

III University of Alabama at Birmingham, School of Dentistry, Birmingham, AL.

If Boston Biostatistics Research Foundation, Framington, MA

\#\# University at Buffalo, State University of New York, Buffalo, NY

*** BioMimetic Therapeutics, Franklin, TN.
} 
$\mathrm{P}$ eriodontal researchers and clinicians, in an effort to develop effective regenerative therapies, have sought to understand key events involved in the regeneration of the periodontium. An increased knowledge of specific cellular response and function within the periodontium has led to the development of numerous treatment modalities exhibiting different degrees of success. Treatments including "grafting" with bone or bone substitutes; ${ }^{1-17}$ stimulation of cells with growth factors, hormones, or extracelluar matrix proteins; $6,7,18-25$ cell occlusive barrier membranes for selective cell growth in periodontal defects; ${ }^{26-32}$ and modification of the tooth root surface ${ }^{33-38}$ have all been explored for their ability to predictably regenerate the periodontium. Although some treatments have yielded promising results, there remains a need for a treatment that leads to faster and more predictable regeneration of the periodontium. Building on these results, as well as knowledge gained from within the field of tissue engineering, periodontal treatment modalities now strive to provide one or more of the following to enhance periodontal regeneration: appropriate matrices, biologic mediators, and/or precursor cells. By providing these building blocks, the process of regeneration may be enhanced, resulting in an earlier and greater regenerative response.

The therapeutic system used in this study combines purified recombinant (synthetic) human platelet-derived growth factor (rhPDGF-BB) with a biocompatible osteoconductive, synthetic scaffold (beta-tricalcium phosphate $[\beta-\mathrm{TCP}]$ ) for the treatment of osseous defects resulting from periodontal disease.

$\beta$-TCP is a purified, multicrystalline, and porous form of calcium phosphate with a $\mathrm{Ca} / \mathrm{PO}_{4}$ ratio similar to natural bone mineral. Extensive animal and human clinical studies over the past 25 years have demonstrated the biocompatibility of $\beta$-TCP, including incorporation into host bone in various skeletal sites, remodeling, and eventual replacement by the host bone. ${ }^{39-42} \beta$-TCP is marketed as a bone void filler for orthopedic and dental applications worldwide.

PDGF is a well-characterized tissue growth factor currently marketed in a gel formulation for the treatment of chronic cutaneous ulcers in the lower extremities of diabetics. In periodontics, numerous studies have demonstrated its mitogenic and chemotactic effects on periodontal ligament (PDL) and alveolar bone cells, as well as its ability to promote the regeneration of bone, ligament, and cementum in animals and humans. 6,7,22,24,43-55 An initial human clinical trial demonstrated that the application of $0.15 \mathrm{mg} / \mathrm{ml}$ rhPDGF-BB and $0.15 \mathrm{mg} / \mathrm{ml}$ recombinant human insulin-like growth factor I (rhIGF-I) resulted in a significant improvement of bone fill in periodontal de- fects compared to conventional surgery plus a vehicle control. ${ }^{22}$ Additionally, results of a pilot human trial indicated that the application of 0.5 to $1.0 \mathrm{mg} / \mathrm{ml}$ rhPDGF-BB in allograft resulted in the regeneration of bone, ligament, and cementum as demonstrated by blinded histologic evaluation. ${ }^{6,7}$

The aim of this randomized controlled trial (RCT) was to evaluate the safety and efficacy of rhPDGFBB delivered in $\beta$-TCP for the treatment of periodontal osseous defects.

\section{MATERIALS AND METHODS}

\section{Study Participants}

Male and female subjects, 25 to 75 years of age, each with one interproximal periodontal defect requiring surgical treatment, were included in the study. Other inclusion criteria included the following: 1) a probing depth measuring $7 \mathrm{~mm}$ or greater at baseline; 2) following debridement, a $4 \mathrm{~mm}$ or greater vertical bone defect depth (BD) with at least one intact bony wall; 3) sufficient keratinized tissue to allow complete tissue coverage of the defect; 4) a radiographic base of the defect at least $3 \mathrm{~mm}$ coronal to the apex of the tooth; and 5) no evidence of localized aggressive periodontitis. Smokers were allowed to use up to one pack of cigarettes per day.

Patients were not admitted to the study if any of the following criteria were present: 1 ) failure to maintain adequate oral hygiene during the lead-in phase; 2 ) pregnant women or women intending to become pregnant during this study period; 3 ) history within the last 6 months of oral cancer or human immunodeficiency virus (HIV); 4) history within the last year of previous periodontal surgery on the study tooth; 5) the study tooth exhibiting mobility of greater than grade $2 ; 6$ ) the study tooth exhibiting a Class 3 furcation defect; 7) clinical or radiographic signs of untreated acute infection at the surgical site, apical pathology, root fracture, severe root irregularities, cemental pearls; cemento-enamel projections not easily removed by odontoplasty, untreated carious lesions at the cemento-enamel junction (CEJ) or on the root surface, subgingival restorations and/or restorations with open margins at or below the CEJ; 8) history within the last 6 months of weekly or more frequent use of smokeless chewing tobacco, pipe or cigar smoking, or smoking more than 20 cigarettes per day; 9) allergy to yeast-derived products; or 10) subjects using an investigational therapy or approved therapy for investigational use within 30 days of surgery.

\section{Sample Size Calculation}

The estimated sample size for this trial was calculated using CAL and relied on the normal deviate distributions for a one-sided $t$ test comparing two groups of independent and randomly allocated subjects. Each 
participating individual contributed one osseous defect to the trial.

The number of subjects needed per treatment group was calculated using the following assumptions: $\mathrm{N} \geq 2(\mathrm{SD})^{2}(1.645+0.84)^{2} \mathrm{D}^{2}$, where normal deviate at $\alpha=0.05$ (one-sided) and at $\beta=0.20$ ( $80 \%$ power); SD of CAL change $=2.0 \mathrm{~mm}$; and detectable difference $(D)$ in $C A L=1.0 \mathrm{~mm}$.

When comparing to the control ( $\beta$-TCP + buffer), 50 subjects per group were required. Conservatively allowing for a $15 \%$ attrition, each group was randomly allocated 60 subjects to allow the statistical power to be met.

\section{Study Design and Procedures}

This triple-blind, prospective, and parallel-arm RCT was conducted at eleven clinical centers (of $M N$ and MLN, WVG, MKM, RTK, JTM, JEH, BSM, KSM, PKM, DWP, and $\mathrm{TJH}$ ) in subjects requiring surgical treatment of a periodontal osseous defect. A meeting of investigators was conducted prior to the study initiation to train the investigators on the study protocol including the standardization of patient selection, measurement and surgical techniques, and postoperative management. Eligible subjects were randomized in equal proportions to three treatment groups of $\sim 60$ subjects each ( 180 total patients) using a variable block design: group 1: $\beta$-TCP, with buffer containing $0.3 \mathrm{mg} / \mathrm{ml}$ rhPDGF-BB; group 2: $\beta$-TCP, with buffer containing $1.0 \mathrm{mg} / \mathrm{ml}$ rhPDGF-BB; and group 3: $\beta$-TCP, with buffer alone (active control).

Informed consent was obtained at the initial visit. Subjects were assessed at the screening and baseline visits to determine eligibility. Prior to initiating the baseline measurements, intra- and interexaminer calibrations were performed on patients at each center to ensure reproducibility and consistency by each investigator (intraexaminer) as well as across all study centers (interexaminer). Each subject received standard care, including full-mouth scaling, root planing, and oral hygiene instruction within 2 months of the baseline clinical measurements to minimize bacterial insult and reduce variability between lesions at baseline.

Surgical treatment consisted of the administration of local anesthesia followed by reflection of full thickness buccal and lingual flaps to allow adequate visualization of the treatment site. The osseous defect was thoroughly debrided, and the root surfaces were planed using hand, ultrasonic, and rotary instrumentation as necessary to remove root surface accretions and enamel projections. Direct measurements of the intrabony defect were then obtained, including vertical $\mathrm{BD}$, bone defect width (W) from the root surface to the farthest bone wall, and the number of bone walls present (i.e., 1 to 3 ). If the bone defect was $\geq 4 \mathrm{~mm}$ vertically, final subject eligibility was confirmed, and the tooth root surfaces were decontaminated with a tetracycline paste prepared by mixing the contents of one 250-mg capsule with sterile saline. A blinded study kit was selected for each patient according to a randomization schedule. The $\beta$-TCP was mixed with the buffer with or without rhPDGF-BB and allowed to sit for $\sim 10$ minutes to permit binding of the rhPDGFBB protein to the $\beta$-TCP before being placed into the osseous defect. The gingival flaps were then secured with non-resorbable sutures to achieve complete soft tissue coverage of the surgical site. The duration of the study was 6 months following surgery. Postoperative visits at days 3 to 5,6 to 9,12 to 15 , and 19 to 24 and weeks $6,12,18$, and 24 were scheduled to monitor safety and obtain clinical and radiographic data for subsequent analysis. Following completion of the 6month assessments, surgical reentry was performed on a small number of patients to visualize the area of the original defect.

\section{Endpoints}

Effectiveness measurements included the soft-tissue measurements change in gingival clinical attachment level (CAL) and degree of post-surgical recession and the hard tissue measurements radiographic linear bone growth (LBG) and radiographic percent bone fill (\% BF) between baseline and 6 months post-surgery comparing the rhPDGF-BB treated groups (groups 1 or 2 ) to the active control (group 3 ).

Radiographs were obtained within 2 months prior to the baseline surgery using bite planes and paralleling techniques and holders. ${ }^{\dagger \dagger}$ The quality of the films was assessed by the investigator prior to the release of the patient to ensure diagnostic quality. Radiographs from all clinical centers were sent to a separate, independent, centralized, and blinded radiographic center (of MSR). The films were digitized, and linear radiographic measurements were analyzed for bone changes. The following measurements, illustrated in Figure 1, were taken on the baseline and 6-month digitized periapical radiographic images: CEJ to base of bone defect, CEJ to crest of bone, and CEJ to root apex.

The following formula was used to determine LBG: LBG $=$ CEJ to base of defect at baseline - CEJ to base of defect at 6 months.

Percent bone fill was calculated by dividing LBG by the depth of the original bone defect. An initial pilot study was performed on 25 radiographs to confirm the feasibility of using these radiographic measurements. A separate intraexaminer calibration was also performed to confirm the reproducibility of the radiographic measurements. This assessment included a review of a representative sampling of radiographs measured at two different time points $(\sim 1$ month

$\dagger \dagger \dagger$ Dentsply Rinn, Elgin, IL. 

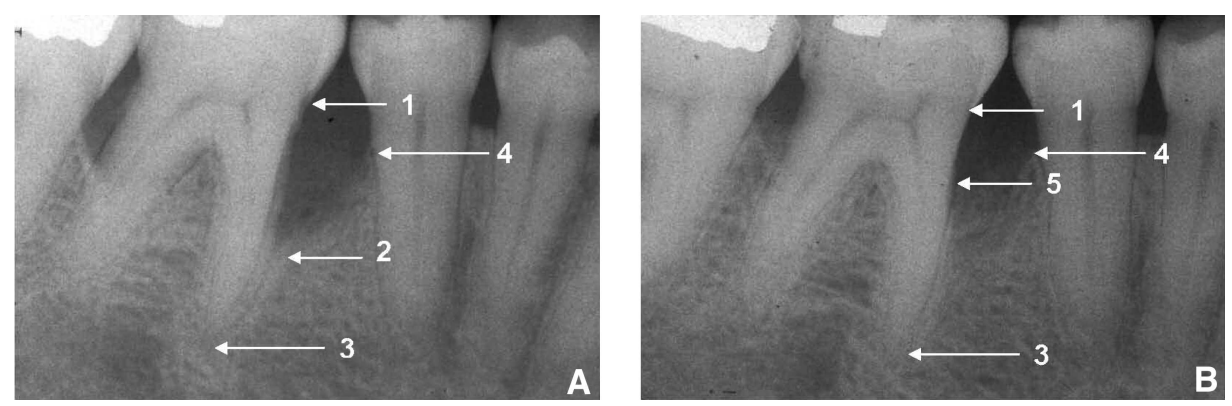

Figure I.

Representative radiographic case from group I ( $0.3 \mathrm{mg} / \mathrm{m} / \mathrm{mPD} G F-B B)$ demonstrating the appearance of bone fill in the original osseous defect. A) Baseline; B) 6 months post-surgery. Note the significant increase in radiographic fill of the defect. Radiographic assessment found $3.11 \mathrm{~mm} \mathrm{LBG}$ and $47 \% \mathrm{BF}$. Arrows with numbers denote the following: I) (E); 2) base of bone defect at baseline; 3) root apex; 4) bone crest; and 5) new base of defect at 6 months.

apart) and demonstrated a 3\% variability between measurements.

For any paired baseline and 6-month radiographs demonstrating $\geq 15 \%$ difference in the measurement from CEJ to root apex, measurements were corrected for elongation or foreshortening.

Safety was monitored throughout the trial by assessing the frequency and severity of adverse events (clinical and radiographic). The relationship of each adverse event to the treatment rendered (test or control) was assessed in a blinded fashion by the investigator. All adverse events were reported regardless of causality, including events that were normal sequelae related to the surgical procedure.

The study was initiated following Food and Drug Administration (FDA) and institutional review board (IRB) approvals and was monitored for compliance to good clinical practices (GCPs) by an independent contract research organization (CRO). ${ }^{\ddagger} \neq$ Test materials $\S \S \S$ were supplied to independent contract manufacturing facilities $|\||\|| \mid$ III where they were labeled using masked rub-off labels according to a randomization code generated by the CRO.

\section{Statistical Methods}

The sample size for this trial was calculated using the outcome variable CAL, and relied on the normal deviate distributions for a one-sided $t$ test comparing two groups of independent and randomly allocated subjects. Each patient contributed one osseous defect to the trial. The primary endpoint was change in CAL between baseline and 6 months for group 1 versus group 3. As prespecified in the statistical plan, significance between groups 2 and 3 was assessed only if statistical significance was observed in the primary comparison. Categorical measurements were displayed as counts and percents, and continuous variables were displayed as means, medians, standard errors, and ranges. Statistical comparisons between the test product treatment groups (groups 1 and 2) and the control group (group 3) were made using chi-square and Fisher's exact tests for categorical variables and $t$ tests or analysis of variance (ANOVA) methods for continuous variables. Comparisons between treatment groups for ordinal variables were made using Cochran-Mantel-Haenszel methods. An area under the curve (AUC) analysis was performed to assess the cumulative change in CAL between baseline and 6 months. $P \leq 0.05$ (one-sided) was considered to be statistically significant for AUC, CAL, LBG, and \% BF. A standard stratification of the cumulative $\% \mathrm{BF}$ was performed examining the distribution of outcomes.

Safety and effectiveness data were $100 \%$ verified against source documents, and the statistical analyses were performed by the CRO. Safety data were assessed by the frequency and severity of adverse events as evaluated clinically and radiographically.

\section{RESULTS}

\section{Demographics and Patient Follow-Ulp}

There were no statistically significant differences in clinical baseline characteristics observed among the treatment groups (including CAL, PD, GR, and defect location and classification) (Table 1). The patient population was balanced for age, ethnicity, and gender, and no significant differences were observed among the three treatment groups for reported medical and dental histories (Table 2). Follow-up was completed on 178 of the 180 patients enrolled in the trial (two were lost to follow-up). One patient was disqualified from the efficacy analysis due to an acute endodontic infection at baseline. Consequently, the statistical analysis is based on clinical data from 177 patients $(98.3 \%)$ and radiographs from 173 patients $(96.1 \%)$. Four subjects were omitted from the radiographic analysis because the films were not of diagnostic quality.

Analyses to assess the reliability of CAL measurements were performed by measuring the intraexaminer reproducibility and interexaminer consistency. These analyses provided the measure of reliability

\footnotetext{
†キ Target Health, New York, NY.

$\S \S \S$ GEM 21S, BioMimetic Therapeutics, Franklin, TN.

\|ll\| Omnicare, King of Prussia, PA.

ๆๆๆ Proclinical, Phoenixville, PA.
} 
Table I.

\section{No Significant Difference in Baseline Clinical Characteristics Between Groups}

\begin{tabular}{|c|c|c|c|c|}
\hline Baseline Characteristics & Group I $(N=60)$ & Group $2(N=6 \mid)$ & Group $3(N=59)$ & $P$ Value \\
\hline \multicolumn{5}{|l|}{ CAL $(\mathrm{mm})$} \\
\hline Mean \pm SE & $9.1 \pm 0.2$ & $8.8 \pm 0.2$ & $8.8 \pm 0.2$ & $0.500 *$ \\
\hline Range & 7 to 14 & 7 to 13 & 6 to 13 & \\
\hline \multicolumn{5}{|l|}{$\mathrm{PD}(\mathrm{mm})$} \\
\hline Mean \pm SE & $8.6 \pm 0.2$ & $8.2 \pm 0.2$ & $8.3 \pm 0.2$ & $0.167 *$ \\
\hline Range & 7 to 14 & 7 to 13 & 7 to 14 & \\
\hline \multicolumn{5}{|l|}{$\mathrm{GR}(\mathrm{mm})$} \\
\hline Mean \pm SE & $0.5 \pm 0.2$ & $0.6 \pm 0.2$ & $0.5 \pm 0.1$ & $0.891 *$ \\
\hline Range & -2 to 4 & -2 to 5 & -2 to 4 & \\
\hline \multicolumn{5}{|l|}{ Defect location } \\
\hline Maxillary & $21(35 \%)$ & $24(39.3 \%)$ & $18(30.5 \%)$ & $0.598 *$ \\
\hline Mandibular & $39(65 \%)$ & $37(60.7 \%)$ & $41(69.5 \%)$ & $0.612^{\dagger}$ \\
\hline MB & $25(41.7 \%)$ & $27(44.3 \%)$ & $27(45.8 \%)$ & \\
\hline B & $0(0.0 \%)$ & $0(0.0 \%)$ & $0(0.0 \%)$ & \\
\hline DB & $21(35.0 \%)$ & $17(27.9 \%)$ & $15(25.4 \%)$ & \\
\hline ML & $8(13.3 \%)$ & $14(23.0 \%)$ & $10(16.9 \%)$ & \\
\hline $\mathrm{L}$ & $0(0.0 \%)$ & $0(0.0 \%)$ & $0(0.0 \%)$ & \\
\hline $\mathrm{DL}$ & $6(10.0 \%)$ & $3(4.9 \%)$ & $7(11.9 \%)$ & \\
\hline Defect classification (coronal portion) & & & & $0.301^{\dagger}$ \\
\hline I-wall & $20(33.3 \%)$ & $17(27.9 \%)$ & $19(32.2 \%)$ & \\
\hline 2-wall & $26(43.3 \%)$ & $32(52.5 \%)$ & $26(44.1 \%)$ & \\
\hline 3-wall & $5(8.3 \%)$ & $8(13.1 \%)$ & II (I8.6\%) & \\
\hline Circumferential & $9(15.0 \%)$ & $4(6.6 \%)$ & $3(5.1 \%)$ & \\
\hline Defect tooth & & & & $0.713^{\dagger}$ \\
\hline Multirooted & $35(58.3 \%)$ & $33(54.1 \%)$ & $30(50.8 \%)$ & \\
\hline Single-rooted & $25(41.7 \%)$ & $28(45.9 \%)$ & $29(49.2 \%)$ & \\
\hline Vertical bone defect depth $(\mathrm{mm}$; mean $\pm \mathrm{SE})$ & $6.0 \pm 0.2$ & $5.7 \pm 0.2$ & $5.7 \pm 0.2$ & $0.357 *$ \\
\hline Width of osseous defect (mean $\pm \mathrm{SE}$ ) & $3.7 \pm 0.2$ & $3.5 \pm 0.1$ & $3.7 \pm 0.1$ & $0.606 *$ \\
\hline
\end{tabular}

* $P$ value (one-way ANOVA).

$\dagger P$ value (chi-square test).

$\mathrm{MB}=$ mesio-buccal; $\mathrm{B}=$ buccal; $\mathrm{DB}=$ disto-buccal; $M L=$ mesio-lingual; $\mathrm{L}=$ lingual; $\mathrm{DL}=$ disto-lingual.

("kappa") as follows: kappa = 0.9596 demonstrated intraexaminer reproducibility; kappa $=0.8901 \mathrm{dem}$ onstrated interexaminer consistency.

\section{Effectiveness}

The results from the statistical analyses revealed clinical and radiographic benefits for the two treatment groups incorporating 0.3 or $1.0 \mathrm{mg} / \mathrm{ml}$ rhPDGF-BB (groups 1 and 2, respectively), compared to the active control, $\beta$-TCP, group (group 3). A representative case treated with rhPDGF is shown in Figure 2.

At 3 months post-surgery, the mean CAL gain was significantly greater in group 1 versus group 3 (3.8 \pm 0.2 versus $3.3 \pm 0.2 \mathrm{~mm} ; P=0.032$ ), thereby indicat- ing a significant early benefit of rhPDGF-BB for the gain in CAL. At 6 months post-surgery, this trend continued to favor group 1 over group 3 (mean gain of $3.8 \pm 0.2$ versus $3.5 \pm 0.2 \mathrm{~mm}$, respectively), although this difference was not statistically significant $(P=0.107)$. Overall, this early acceleration of CAL gain led to group 1 exhibiting a significantly greater rate of CAL gain between baseline and 6 months than group 3 as assessed by the AUC (68.4- versus 60.1-mm weeks; $P=0.033$ ) (Fig. 3). Additionally, there was less GR at 3 months in group 1 compared to group 3 ( $P=$ $0.04)$; at 6 months, GR for group 1 remained unchanged, whereas there was a slight gain in gingival height for group 3 resulting in comparable GR $(P>0.05)$. 
Table 2.

\section{No Significant Differences in Demographic Characteristics Between Groups}

\begin{tabular}{|c|c|c|c|c|}
\hline & Group I $(N=60)$ & Group $2(N=6 \mathrm{l})$ & Group $3(N=59)$ & $P$ Value \\
\hline Gender & & & & $0.074 *$ \\
\hline Female & 31 (51.7\%) & $20(32.8 \%)$ & $21(35.6 \%)$ & \\
\hline Male & 29 (48.3\%) & $41(67.2 \%)$ & 38 (64.4\%) & \\
\hline Ethnicity & & & & $0.387^{\dagger}$ \\
\hline White & 33 (55.0\%) & 37 (60.7\%) & 37 (62.7\%) & \\
\hline Hispanic & $6(10.0 \%)$ & $4(6.6 \%)$ & $8(\mid 3.6 \%)$ & \\
\hline Asian & $10(16.7 \%)$ & $13(21.3 \%)$ & $9(15.3 \%)$ & \\
\hline African American & $11(18.3 \%)$ & $5(8.2 \%)$ & $5(8.5 \%)$ & \\
\hline Native American & $0(0.0 \%)$ & $0(0.0 \%)$ & $0(0.0 \%)$ & \\
\hline Other & $0(0.0 \%)$ & $2(3.3 \%)$ & $0(0.0 \%)$ & \\
\hline Age (years) & & & & $0.222^{\ddagger}$ \\
\hline Mean \pm SE & $49.4 \pm 1.3$ & $50.4 \pm 1.7$ & $52.8 \pm 1.2$ & \\
\hline Minimum/maximum & $27 / 67$ & $23 / 73$ & 29/71 & \\
\hline \multicolumn{5}{|l|}{ Medical condition/medications } \\
\hline \multicolumn{5}{|l|}{ Diabetes (type I or II) } \\
\hline Yes & $2(3.3 \%)$ & $7(11.5 \%)$ & $6(10.2 \%)$ & $0.163^{\dagger}$ \\
\hline No & $58(96.7 \%)$ & $54(88.5 \%)$ & $53(89.8 \%)$ & \\
\hline \multicolumn{5}{|l|}{$\begin{array}{l}\text { Chronic non-steroidal anti- } \\
\text { inflammatory drug use }\end{array}$} \\
\hline Yes & $10(16.7 \%)$ & $7(11.5 \%)$ & $15(25.4 \%)$ & $0.268^{\dagger}$ \\
\hline No & $50(83.3 \%)$ & $54(88.5 \%)$ & $44(74.6 \%)$ & \\
\hline \multicolumn{5}{|l|}{ Smoking history } \\
\hline Current smoker & $12(20.0 \%)$ & $19(31.1 \%)$ & 12 (20.3\%) & $0.262^{\ddagger}$ \\
\hline $\begin{array}{l}\text { Number of cigarettes smoked } \\
\text { daily (mean } \pm \text { SE) }\end{array}$ & $11.6 \pm 1.6$ & $9.5 \pm 1.5$ & $8.2 \pm 2.0$ & $0.429^{\ddagger}$ \\
\hline $\begin{array}{l}\text { Number of cigars smoked } \\
\text { weekly (mean } \pm \mathrm{SE} \text { ) }\end{array}$ & $0.0 \pm 0.0$ & $0.0 \pm 0.0$ & $0.1 \pm 0.1$ & $0.438^{\ddagger}$ \\
\hline $\begin{array}{l}\text { Number of pipes smoked } \\
\text { weekly (mean } \pm \mathrm{SE} \text { ) }\end{array}$ & $0.0 \pm 0.0$ & $0.0 \pm 0.0$ & $0.6 \pm 0.6$ & $0.281^{\ddagger}$ \\
\hline
\end{tabular}

* Chi-square test.

$\dagger$ Fisher's exact test.

$\ddagger$ One-way ANOVA

In addition to the observed clinical benefits on the soft tissue parameters of CAL and GR, radiographic analyses of LBG and \% BF revealed a significant improvement in bone gain for groups 1 or 2 versus group 3. A representative radiographic case for group 1 is shown in Figure 1. LBG was significantly improved in group 1 (2.6 $\pm 0.2 \mathrm{~mm})$ compared to group 3 (0.9 \pm $0.1 \mathrm{~mm} ; P<0.001)$ and in group $2(1.5 \pm 0.2 \mathrm{~mm})$ compared to group 3 ( $P=0.021$; Fig. 4$)$.

Percent BF was defined as the percentage of the original osseous defect filled with new bone as measured radiographically. Percent BF was significantly increased at 6 months post-surgery in group 1 (57\% $\pm 6 \%)$ and group $2(34 \% \pm 4 \%)$ when compared to group $3(18 \% \pm 6 \%)$, yielding a $P<0.001$ and
$P=0.019$, respectively (Fig. 5A). Subgroup analyses of $\% \mathrm{BF}$ were also performed to assess the effects of smoking versus non-smoking and of defect morphology. These analyses demonstrated that rhPDGF treatment improved bone fill in smokers and in all defect types (Figs. 5B and 5C, respectively).

To assess the predictability of the responses, the cumulative percent bone fill was computed and the cumulative distribution functions are displayed in Figure 6 . The three treatment groups demonstrated separation, with group 1 consistently demonstrating the best effectiveness. The cumulative distributions were highest for group 1 followed by groups 2 and 3, respectively, for any \% BF threshold. That is, at any given point on the curves, the cumulative percentage 

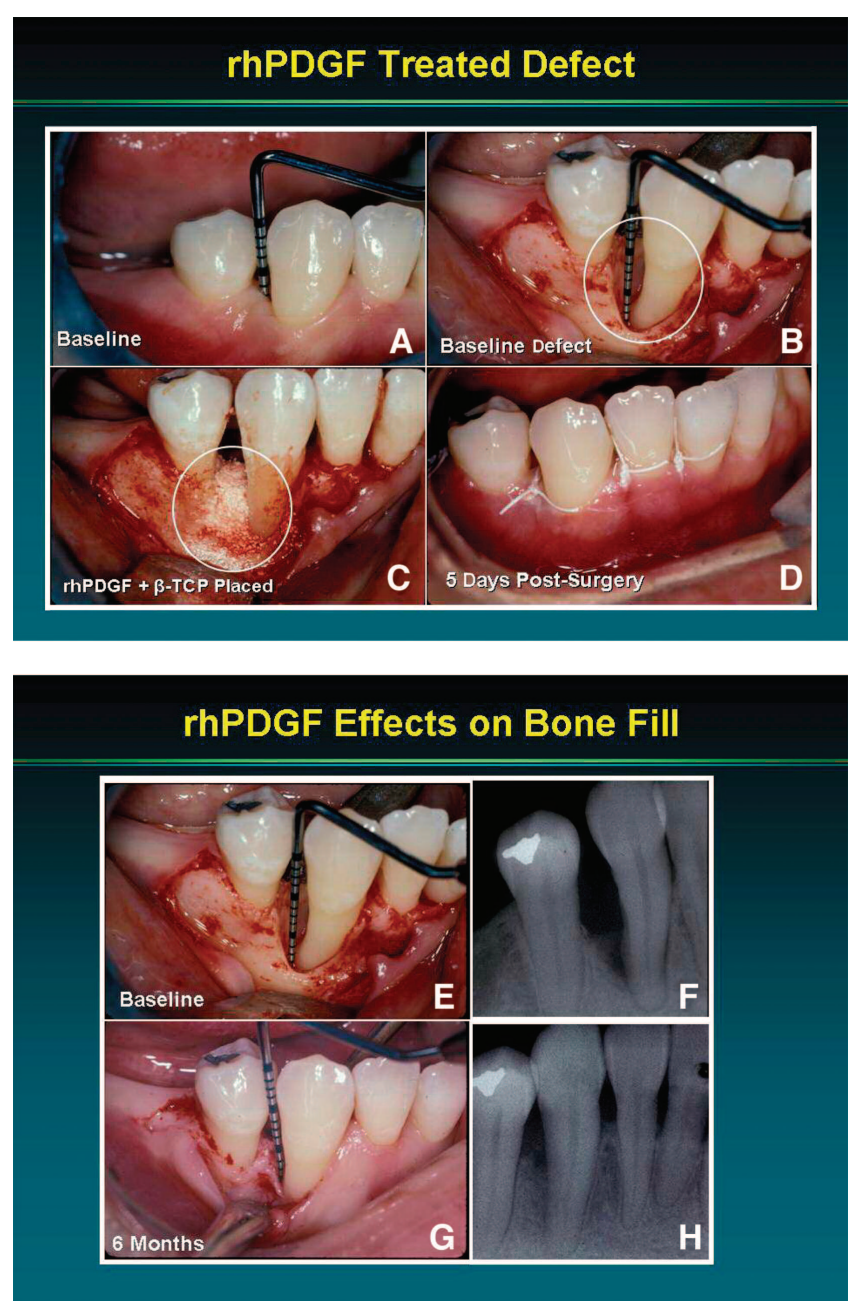

Figure 2.

Representative rhPDGF treated case. A) Baseline; B) initial osseous defect on the distal of tooth \#22 following thorough debridement; C) $\beta$-TCP + rhPDGF completely filling the defect; D) 3-5 days postsurgery showing excellent healing; $\mathbf{E})$ clinical and $(\mathbf{F})$ radiographic appearance of baseline defect; $\mathbf{G )}$ 6-month surgical reentry showing clinical defect fill; and $\boldsymbol{H}$ ) 6-month radiograph showing defect fill.

of patients with the greatest bone fill was highest in group 1 compared to either group 2 or 3 . For example, $50 \%$ of patients in group 1 exhibited $>49 \%$ bone fill compared to $20 \%$ bone fill in group 3 . A Wilcoxon rank sum test was used to compare the cumulative distributions for groups $1(P<0.0001)$ and $2(P=0.0572)$ versus group 3 . This overall comparison demonstrated a consistent advantage for group 1 over group 3 , which was independent of the $\%$ BF threshold.

\section{Safety}

The safety assessment included clinical examinations and radiographs of adverse events, both serious or non-serious and related or unrelated, to the treatment groups. The most frequently experienced adverse event for all treatment groups was study site

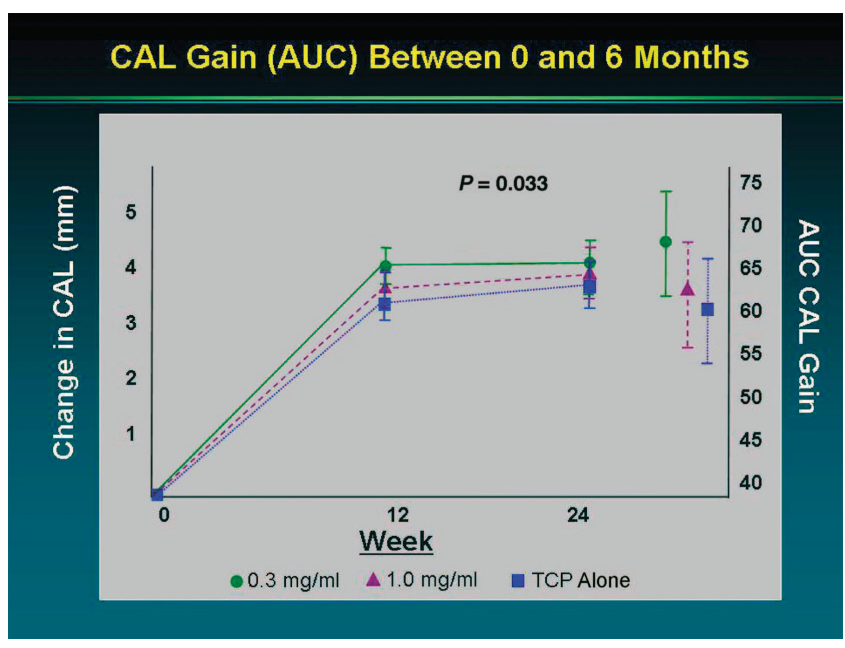

Figure 3.

rhPDGF significantly improved CAL gain between baseline and 6 months as assessed by clinical improvement in CAL as a function of time.

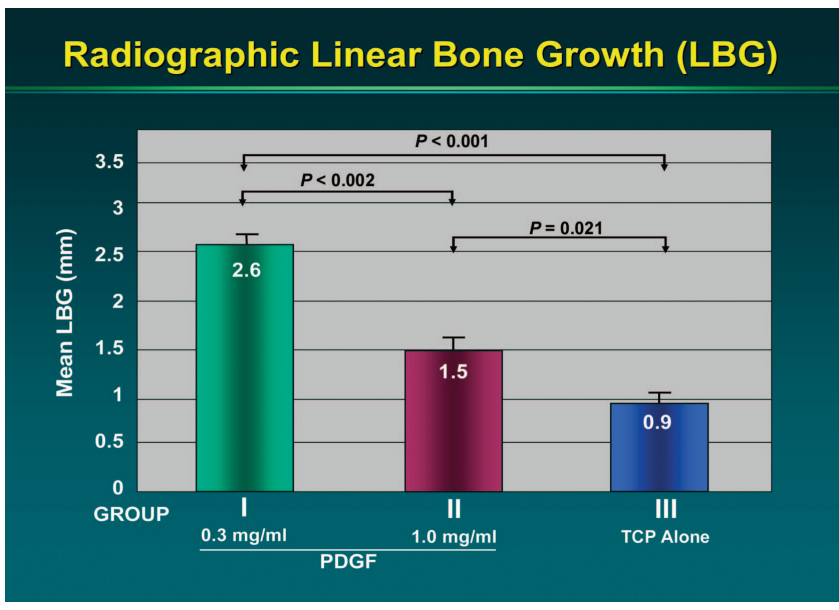

Figure 4.

rhPDGF-BB plus $\beta$-TCP significantly improved LBG compared to $\beta$-TCP plus buffer.

pain, a normal sequela to the surgical procedure (typically resolved within 1 week of surgery), followed by headache. The study found no significant differences in adverse events across the treatment groups. The assessment of radiographs revealed no findings outside of normal limits for any treatment group.

\section{DISCUSSION}

Earlier clinical studies provided human histologic evidence ("proof of principle") that the combination of purified rhPDGF-BB and a scaffolding material (bone allograft) could result in substantial periodontal regeneration. ${ }^{6,7}$ The present study was designed to evaluate the safety and effectiveness of rhPDGF-BB 

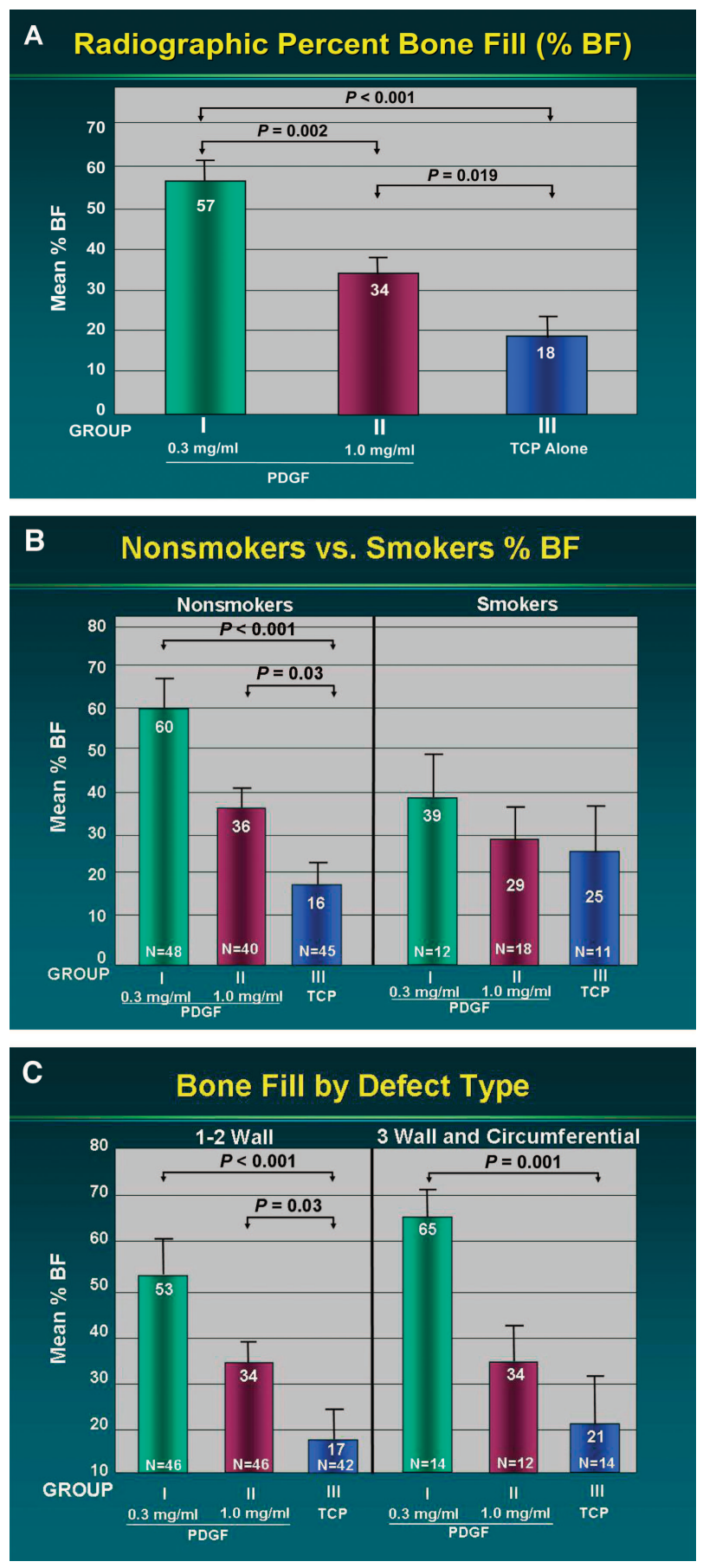

Figure 5 .

A) rhPDGF-BB plus $\beta$-TCP significantly improved $\%$ BF of all bone defects compared to $\beta$-TCP plus buffer. B) rhPDGF stimulated a significant improvement in bone fill in smokers and non-smokers ( $P<0.001$ ), although bone fill tended to be greater in non-smokers compared to smokers ( $P=0.15$ in the $0.3 \mathrm{mg} / \mathrm{ml}$ rhPDGF group). $\boldsymbol{C}$ ) rhPDGF treatment also resulted in significantly improved bone fill in I-, 2-, and 3-wall defects ( $<<0.001)$; there was no significant difference in bone fill between 1 - and 2-wall defects compared to 3-wall and circumferential defects ( $P=0.40$ in the $0.3 \mathrm{mg} / \mathrm{ml}$ group).

\section{$\%$ Bone Fill Cumulative Distribution}

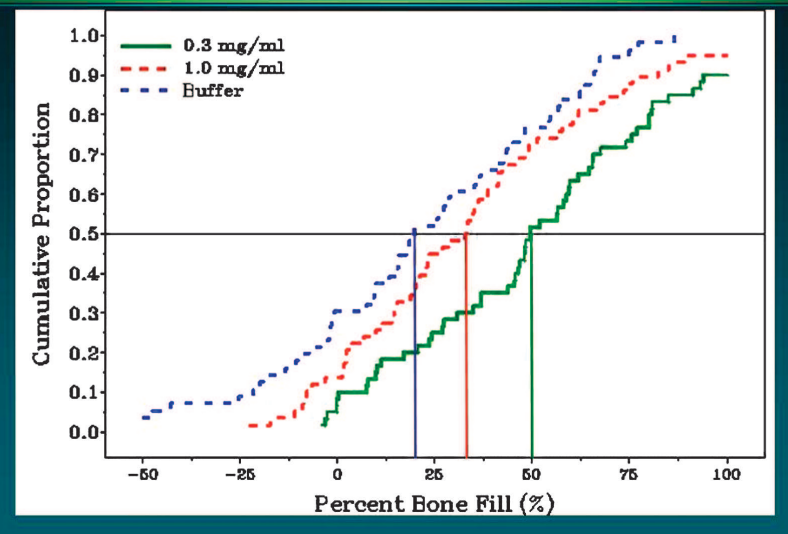

Figure 6.

Percent bone fill cumulative distribution. The cumulative distributions were highest for group I as this group exceeded the response seen in groups 2 and 3 for any \% BF threshold. For example, the horizontal line illustrates that half of the patients in group I achieved greater than $49 \%$ bone fill, whereas half of the patients in group 3 achieved only $20 \%$ bone fill. A Wilcoxon rank sum test was used to compare the cumulative distributions for groups I $(\mathrm{P}<0.0001)$ and 2 $(P=0.0572)$ versus group 3 .

and a synthetic matrix in the largest prospective, randomized, blinded, controlled, and multicenter human clinical trial published to date on a periodontal regenerative therapy. A parallel design was used with each patient contributing one defect, thereby eliminating the potential for crossover treatment effects by the growth factor. Randomization, the large sample size, and the defect entry criteria assured comparable defects across each treatment group, as evidenced by the data shown in Tables 1 and 2 . The current study was designed to include practitioners in private office settings and academic research clinics and was independently monitored and analyzed in an attempt to rigorously assess the safety and effectiveness of this therapy.

The results of this clinical study confirmed earlier extensive studies demonstrating the safety of rhPDGF in multiple animal and human studies. ${ }^{6,7,56,57}$ Additionally, this study further confirms the beneficial effects of rhPDGF observed in earlier human histologic periodontal studies. ${ }^{6,7}$ The rhPDGF-BB $(0.3 \mathrm{mg} / \mathrm{ml}$ dose) significantly improved bone fill (LBG and \% $\mathrm{BF}$ ) assessed radiographically at 6 months and soft tissue outcomes at 3 months (CAL gain and reduced GR) assessed clinically, compared to the active control, $\beta$-TCP. At 6 months, the CAL gain in group 1 remained greater than group 3; however, the difference was not significant due to an increase in the group 3 score. Significant improvements in both soft tissue 
and bone measurements are important clinical findings and are likely the result of PDGF's stimulatory effects on periodontal ligament and bone cells. ${ }^{24,43-55}$

The finding that the $0.3 \mathrm{mg} / \mathrm{ml}$ dose of rhPDGF-BB was more effective than the $1.0 \mathrm{mg} / \mathrm{ml}$ dose is consistent with preclinical studies in a canine model (unpublished observations) and reflects similar results observed for other growth factors and cytokines, demonstrating the potential for an inverse dose effect with many biological mediators. This finding underscores a fundamental observation that cytokines, such as PDGF, may have differing effects based on local concentration. ${ }^{52-54}$ Perhaps the most well known example of this phenomenon is insulin, which also exhibits a classic bell-shaped dose response curve in which a low dose is ineffective, the proper dose provides the desired biological response, and a dose that is too high is life-threatening. Although apparently not as effective, even the high dose of rhPDGF-BB in this trial did not result in any adverse effects.

The significant increase in the rate of CAL gain and bone fill at 6 months is, to our knowledge, a unique finding. Interestingly, a significant difference in bone fill between study groups does not routinely correlate with a significant difference in CAL, and vice versa, particularly when the control employed is itself a bone void filler material. It has been shown that although the latter materials frequently do not lead to periodontal regeneration, they do result in the filling of the osseous defect, which leads to substantial CAL gain. It is thus more difficult to show significant improvements in CAL between test and control groups when the control group receives a bone graft and/or bone graft substitute rather than just open flap debridement alone. For example, no significant difference in CAL gain was observed when a bovine bone mineral with synthetic peptide was compared to the bovine bone mineral alone, although the authors did observe a significant improvement in bone fill. ${ }^{58}$

Given the potential for incongruent results between soft tissue and bone measurements, both types of measurements appear necessary to fully evaluate a periodontal therapy. However, osseous reentry surgery is impractical in all patients in a large multicenter clinical trial such as this, especially when private practice settings are included. Therefore, this study used radiographic analyses for $\mathrm{LBG}$ and \% $\mathrm{BF}$ to provide information related to periodontal bone changes that occurred following treatment. The digitized radiographic format used in this trial, along with the use of standardized methods and computer algorithms, reduces the effect of potential errors encountered with visual interpretation by examiners of a restricted twodimensional representation of the three-dimensional anatomy. Additionally, vertical bone growth adjacent to the root surface was chosen as a key outcome because changes in linear bone levels are easily understood and present a clinically meaningful change in the support of the tooth. We were fortunate in the present study that $\beta$-TCP is absorbed over a period of several months and thus did not obscure the bone fill. Further, because both the controls and test groups included the $\beta$-TCP, any increase in radioopacity that might be caused by residual $\beta$-TCP would presumably be similar in all groups.

It is also noteworthy that radiographic assessment of alveolar bone fill often underestimates actual bone fill measured clinically (i.e., surgical reentry). Thus, the current study results demonstrating a gain in radiographic linear bone growth and percent bone fill may actually underestimate these results as compared to clinical reentry. The use of a centralized radiology review center, which was independent of any clinical center involved in patient care, also has the virtue of being completely blinded and unbiased regarding patient outcome.

In summary, this 180-patient, randomized, controlled, and blinded clinical trial demonstrated that purified rhPDGF-BB mixed with a synthetic bone substitute was safe and effective for the treatment of periodontal osseous defects. The significant increase in the rate of CAL gain, reduction in gingival recession at 3 months, and improvement in bone fill demonstrated in this study provide substantial evidence for the clinical advantages of this therapy. Moreover, the findings of this study substantiate the hypothesis that the addition of rhPDGF-BB improves the effectiveness of the bone substitute.

\section{ACKNOWLEDGMENTS}

Funding for this study was provided by BioMimetic Therapeutics, Franklin, Tennessee. Samuel E. Lynch is president of BioMimetic Therapeutics.

\section{REFERENCES}

1. Stahl SS, Froum SJ, Kushner L. Healing responses of human intraosseous lesions following the use of debridement, grafting and citric acid root treatment. I. Clinical and histologic observation six months postsurgery. J Periodontol 1983;54:67-76.

2. Hiatt WH, Schallhorn RG, Aaronian AJ. The induction of new bone and cementum formation. IV. Microscopic examination of the periodontium following human bone and marrow allograft, autograft and non-graft periodontal regenerative procedures. $J$ Periodontol 1978;49:495-512.

3. Dragoo MR, Sullivan HC. A clinical and histological evaluation of autogenous iliac bone graft in humans. Part I. Wound healing 2 to 8 months. J Periodontol 1973;44:599-613.

4. Parashis A, Andronikaki-Faldami A, Tsiklakis K. Comparison of 2 regenerative procedures. J Periodontol 1998;69:751-758. 
5. Persson GR, Falk H, Laurell A. A retrospective radiographic outcome assessment study of intra-bony defects treated by osseous surgery or by bone graft procedures. J Clin Periodontol 2000;27:104-108.

6. Nevins ML, Camelo M, Nevins M, Schenk RK, Lynch SE. Periodontal regeneration in humans using recombinant human platelet-derived growth factor-BB (rhPDGF-BB) and allogeneic bone. J Periodontol 2003; 74:1282-1292.

7. Camelo M, Nevins ML, Schenk RK, et al. Periodontal regeneration can be achieved in human class 2 furcations using purified recombinant human platelet-derived growth factor BB (rhPDGF-BB) with bone allograft. Int $J$ Periodontics Restorative Dent 2003;23:213-225.

8. Camelo M, Nevins ML, Schenk RK, et al. Clinical, radiographic, and histologic evaluation of human periodontal defected treated with Bio-Oss and BioGide. Int J Periodontics Restorative Dent 1998;18: 321-331.

9. Mellonig JT. Human histologic evaluation of a bovinederived bone xenograft in the treatment of periodontal osseous defects. Int $J$ Periodontics Restorative Dent 2000;20:19-29.

10. Camargo PM, Lekovic V, Weinlaender $M$, et al. A controlled re-entry study on the effectiveness of bovine porous bone mineral used in combination with a collagen membrane of porcine origin in the treatment of intrabony defects in humans. J Clin Periodontol 2000;27:889-896.

11. Houser BE, Mellonig JT, Brunsvold MA, et al. Clinical evaluation of anorganic bovine bone xenograft with a bioabsorbable collagen barrier in the treatment of molar furcation defects. Int $J$ Periodontics Restorative Dent 2001;21:161-169.

12. Snyder AJ, Levin MD, Cutright DE. Alloplastic implants of tricalcium phosphate ceramic in human periodontal osseous defects. J Periodontol 1984;55: 273-277.

13. Baldock WT, Hutchens LH, McFall WT, Simpson DM. An evaluation of tricalcium phosphate implants in human periodontal osseous defects in two subjects. $J$ Periodontol 1985;56:1-7.

14. Stahl SS, Froum SJ. Histologic and clinical responses to porous hydroxylapatite implants in human periodontal defects: Three to twelve months post-implantation. J Periodontol 1987;58:689-695.

15. Froum S, Stahl SS. Human intraosseous healing responses to the placement of tricalcium phosphate ceramic implants. 2. 13 to 18 months. J Periodontol 1987;58:103-109.

16. Strub JR, Gaberthal T. Comparison of tricalcium phosphate and frozen allogenic bone implants in man. J Periodontol 1979;50:624-629.

17. Nery EB. Preliminary clinical studies of bioceramics in periodontal osseous defects. J Periodontol 1978;49: 523-527.

18. Murakami S, Takayama S, Ikezawa K, et al. Regeneration of periodontal tissues by basic fibroblast growth factor. J Periodontal Res 1999;34:425-430.

19. Giannobile WV, Ryan S, Shih M-S, Su DL, Kaplan PL, Chan TCK. Recombinant human osteogenic protein-1 (OP-1) stimulates periodontal wound healing in class 3 furcation defects. J Periodontol 1998;69: 129-137.

20. Cardaropoli G, Leonhardt AS. Enamel matrix proteins in the treatment of deep intrabony defects. $J$ Periodontol 2002;73:501-504.
21. Froum SJ, Weinberg MA, Rosenberg E, Tarnow D. A comparative study utilizing open flap debridement with and without enamel matrix derivative in the treatment of periodontal intrabony defects: A 12-month re-entry study. J Periodontol 2001;72:25-34.

22. Howell TH, Fiorellini JP, Paquette DW, et al. A phase I/II clinical trial to evaluate a combination of recombinant human platelet-derived growth factor-BB and recombinant human insulin-like growth factor-I in subjects with periodontal disease. J Periodontol 1997; 68:1186-1193.

23. Ripamonti U, Crooks J, Petit J-C, Rueger DC. Periodontal tissue regeneration by combined applications of recombinant human osteogenic protein-1 and bone morphogenetic protein-2. A pilot study in baboons (Papio ursinus). Eur J Oral Sci 2001;109:241-248.

24. Wang HL, Pappert T, Castelli W, et al. The effect of platelet-derived growth factor on the cellular response of the periodontium: An autoradiographic study in dogs. J Periodontol 1994;65:429-436.

25. Heard RH, Mellonig JT, Brunsvold MA, Lasho DJ, Meffert RM, Cochran DL. Clinical evaluation of wound healing following multiple exposures to enamel matrix protein derivative in the treatment of intrabony periodontal defects. J Periodontol 2000;71:1715-1721.

26. Machtei EE, Cho MI, Dunford R, et al. Clinical microbiological, and histological factors which influence the success of regenerative periodontal therapy. J Periodontol 1994;65:154-161.

27. Pontoriero R, Lindhe J, Nyman S, et al. Guided tissue regeneration in degree 2 furcation-involved mandibular molars. J Clin Periodontol 1988;15:247-254.

28. Lekovic V, Kenney EB, Kovacevic K, Carranza FA. Evaluation of guided tissue regeneration in Class 2 furcation defects. A clinical re-entry study. $J$ Periodontol 1989;60:694-698.

29. Mellonig JT, Seamons BC, Gray JL, Towle HJ. Clinical evaluation of guided tissue regeneration in the treatment of grade II molar furcation invasions. Int $J$ Periodontics Restorative Dent 1994;14:254-271.

30. Laurell L, Falk H, Fornell J, Johard G, Gottlow J. Clinical use of a bioresorbable matrix barrier in guided tissue regeneration therapy. Case series. J Periodontol 1994;65:967-975.

31. Wang HL, O'Neal RB, Thomas CL, Shyr Y, McNeil RL. Evaluation of an absorbable collagen membrane in treating Class 2 furcation defects. J Periodontol 1994; 65:1029-1036.

32. Caton J, Greenstein G, Zappa U. Synthetic bioabsorbable barrier for regeneration in human periodontal defects. J Periodontol 1994;65:1037-1045.

33. Polson A, Proye MP. Fibrin linkage: A precursor for new attachment. J Periodontol 1983;54:141-147.

34. Polson AM, Proye MP. Effect of root surface alterations on periodontal healing. 2. Citric acid treatment of the denuded root. J Clin Periodontol 1982;9:441-454.

35. Wikesjö UM, Claffey N, Christersson LA, et al. Repair of periodontal furcation defects in beagle dogs following reconstructive surgery including root surface demineralizing with tetracycline hydrochloride and topical fibronectin application. J Clin Periodontol 1988; $15: 73-80$

36. Albair WB, Cobb CM, Killoy WJ. Connective tissue attachment to periodontally diseased roots after citric acid demineralization. J Periodontol 1982;53:515-526.

37. Cole RT, Crigger M, Bogle G, Egelberg J, Selvig KA. Connective tissue regeneration to periodontally 
diseased teeth. A histological study. J Periodontal Res 1980;15:1-9.

38. Frank RM, Fiore-Donno G, Cimasoni G. Cementogenesis and soft tissue attachment after citric acid treatment in a human. An electron microscopic study. $J$ Periodontol 1983;54:389-401.

39. Saffar JL, Colombier ML, Detienville R. Bone formation in tricalcium phosphate-filled periodontal intrabony lesions. Histological observations in humans. J Periodontol 1990;61:209-216.

40. Gatti AM, Zaffe D, Poli GP. Behaviour of tricalcium phosphate and hydroxyapatite granules in sheep bone defects. Biomaterials 1990;11:513-517.

41. Buser D, Hoffmann B, Bernard JP, et al. Evaluation of filling materials in membrane-protected bone defects. A comparative histomorphometric study in the mandible of miniature pigs. Clin Oral Implants Res 1998;9: 137-150.

42. Muschik $M$, Ludwig $R$, Halbhübner $S$, et al. Betatricalcium phosphate as a bone substitute for dorsal spinal fusion in adolescent idiopathic scoliosis: Preliminary results of a prospective clinical study. Eur Spine J 2001;10(Suppl. 2):S178-S184.

43. Lynch SE, Williams RC, Polson AM, et al. A combination of platelet-derived growth factor and insulin-like growth factor enhances periodontal regeneration. $J$ Clin Periodontol 1989;16:545-554.

44. Lynch SE, Castilla GR, Williams RC, et al. The effect of short term application of a combination of plateletderived and insulin-like growth factors on periodontal wound healing. J Periodontol 1991;62:458-467.

45. Lynch SE. The role of growth factors in periodontal repair and regeneration. In: Polson A, ed. Periodontal Regeneration, Current Status and Directions. Chicago: Quintessence Publishing; 1994:179-198.

46. Lynch SE. Introduction. In: Lynch SE, Genco RJ, Marx RE, eds. Tissue Engineering: Applications in Maxillofacial Surgery and Periodontics. Chicago: Quintessence Publishing; 1999:xi-xviii.

47. Giannobile WV, Hernandez RA, Finkelman RD, et al. Comparative effects of platelet-derived growth factor, insulin-like growth factor, individually and in combination on periodontal regeneration in Macaca fascicularis. J Periodontal Res 1996;31:301-312.

48. Park JB, Matsuura M, Han K-Y, et al. Periodontal regeneration in class 3 furcation defects of beagle dogs using guided tissue regeneration therapy with platelet-derived growth factor. J Periodontol 1995;66: 462-477.

49. Cho MI, Lin WL, Genco RJ. Platelet-derived growth factor-modulated guided tissue regeneration therapy. $J$ Periodontol 1995;66:522-530.

50. Rutherford RB, Niekrash CE, Kennedy JE, Charette MF. Platelet-derived and insulin-like growth factors stimulate regeneration of periodontal attachment in monkeys. J Periodontal Res 1992;27:285-290.

51. Reddy MS, Jeffcoat MK. Methods of assessing periodontal regeneration. Periodontol 2000 1999;19: 87-103.

52. Hsieh SC, Graves DT. Pulse application of plateletderived growth factor enhances formation of a mineralizing matrix while continuous application is inhibitory. J Cell Biochem 1998;69:169-180.

53. Yu X, Hsieh SC, Bao W, Graves DT. Temporal expression of PDGF receptors and PDGF regulatory effects on osteoblastic cells in mineralizing cultures. Am J Physiol 1997;272:C1709-C1716.

54. Matsuda N, Lin W, Kumar M, et al. Mitogenic, chemotactic and synthetic responses of rat periodontal ligament fibroblastic cells to polypeptide growth factors in vitro. J Periodontol 1992;63:515-525.

55. Anusaksathien $O$, Jin $Q$, Zhao $M$, Somerman $M J$, Giannobile WV. Effect of sustained delivery of PDGF or its antagonist (PDGF-1308) on tissue-engineered cementum. J Periodontol 2004;75:429-440.

56. Smiell JM, et al. Clinical safety of becaplermin (rhPDGF-BB) gel. Am J Surg 1998;176(Suppl. 2A): 68S-73S.

57. Knight EV, Oldham JW, Mohler MA, Lui S. A review of nonclinical toxicology studies of becaplermin (rhPDGFBB). Am J Surg 1998;176(Suppl. 2A):55S-60S.

58. Yukna R, Krauser J, Callan D, et al. Multi-center clinical comparison of combination of anorganic bovine-derived hydroxyapatite matrix (ABM)/cell binding peptide ( $\mathrm{P}-15)$ and $\mathrm{ABM}$ in human periodontal osseous defects. 6 month results. J Periodontol 2000; 71:1671-1679.

Correspondence: Dr. Samuel E. Lynch, BioMimetic Therapeutics, Inc., 389-A Nichol Mill Ln., Franklin, TN 37067. Fax: 615/844-1281; e-mail: es@biomimetics.com.

Accepted for publication April 15, 2005. 